\title{
KNOWLEDGE, ATTITUDES AND BEHAVIOUR TOWARDS SEXUALLY TRANSMITTED DISEASES IN TURKISH CYPRIOT ADOLESCENTS
}

\author{
Aslı Feride Kaptanoğlu' ${ }^{1}$, Kaya Süer ${ }^{2}$, Hüsrev Diktaş ${ }^{3}$, Evren Hınçal ${ }^{4}$ \\ ${ }^{1}$ Department of Dermatology, Near East University Hospital, Nicosia, North Cyprus \\ ${ }^{2}$ Department of Infectious Diseases and Clinical Microbiology, Near East University Hospital, Nicosia, North Cyprus \\ ${ }^{3}$ Department of Infectious Diseases and Clinical Microbiology, Girne Military Hospital, Kyrenia, North Cyprus \\ ${ }^{4}$ Faculty of Arts and Sciences, Department of Mathematics, Near East University, Nicosia, North Cyprus
}

\section{SUMMARY}

Background: The incidence of sexually transmitted diseases (STDs) is increasing among adolescents all around the world. There may be differences in knowledge and attitudes among different cultures and ethnic populations. The aim of this study is to determine knowledge, attitudes and behaviour of Turkish Cypriot adolescents related to STDs.

Objectives: To assess knowledge of STDs, attitudes towards sexual behaviour and STDs among the secondary school students.

Methods: A cross sectional study, with a sample size of 423 students, was conducted by using a semi-structured questionnaire. Simple random sampling method was applied during the selection of the sample.

Results: The mean age of all participants was $15.61 \pm 1.22,211(49.88 \%)$ of them were male and $212(50.12 \%)$ female. The majority of students $(91.25 \%)$ stated that they had some knowledge about STDs; hovewer, $8.75 \%$ of the participants did not have any knowledge at all. Most of them, $42.32 \%$ described school as a source of information on STDs, nonetheless, only $7.57 \%$ of the group cited health care professionals as the information source. The majority of students (97.64\%) has never been treated for STDs. Among 423 applicants, $93.14 \%$ indicated that they would have appreciated information about STDs during the high school years.

Conclusions: There is a general understanding that the students are willing to participate and are in need of seminars that will be held about STDs during high school attendance. Furthermore, awareness raising educational events on this matter should be reviewed and revised in order to come up with more powerful ways of fighting against STDs transmission in this young population group of Turkish Cypriot (TC) community.

Key words: sexually transmitted diseases, Cyprus, Turkish, adolescent, knowledge, behaviour

Address for correspondence: A. F. Kaptanoğlu, Department of Dermatology, Near East University Hospital, Nicosia, North Cyprus. E-mail: dr.aslikaptanoglu@gmail.com

\section{INTRODUCTION}

Sexually transmitted diseases (STDs) and HIV are recognized as major public health issues in most of the industrialized world. The World Health Organization (WHO) estimates that in the mid 90's, 30 million curable sexually transmitted infections (syphilis, gonorrhea, chlamydia, and trichomoniasis) occurred every year in North America and Western Europe, with additional 18 million cases in Eastern Europe and Central Asia $(1,2)$. STDs deserve attention not only because of their high prevalence but also because of frequently going undetected and untreated with consequential serious reproductive morbidity and mortality (3). Adolescence is a heterogeneous developmental period in terms of sexual behaviour and therefore increases the risk of acquiring sexually transmitted diseases (STDs). However, adolescents have specific needs and challenges related to their well being both physically and mentally, in addition to problems such as unsafe environments, a lack of access to health information and poverty (1). Also, these conditions may vary according to the socioeconomic and cultural factors. In order to develop educational programmes and interventions to control the incidence of STD, local properties such as knowledge, attitudes and behaviours of the adolescents should be defined at first.

Cyprus is an island, located in the eastern part of the Mediterranean Sea, at the south of Turkey. There are mainly two communities living on the island, namely, Turkish Cypriots and Greek Cypriots. During the last 38 years, the island has been divided into two parts due to the conflict between the two communities. Since then, the northern part of the island has been ruled by its own government, which is only recognized by Turkey (4). This international isolation of newly formed government led to a lack of international educational activities among the Turkish Cypriots community. Turkish Cypriots are Muslims by religion and mostly live within the neighbourhood with British islanders. In addition to this, North Cyprus is one of the destinations for casino tourism and entertainment, alongside to its sunny beaches. During the last decade, North Cyprus has become a target country for sex workers from Eastern Europe and the former Republics of Soviet Union. In April 2001, there were 27 nightclubs and 16 pubs in North Cyprus with 774 sex workers. The clientele of nightclubs is primarily composed of young or middle-aged Turkish Cypriots and middle-aged Turkish casino tourists. Pre-marital sex among 
Turkish Cypriot women is strongly condemned while in young men it is either condoned or openly encouraged. This results in a significant demand for sexual services on the part of young men (5). As a result, young Turkish Cypriots may have very unique believes, traditions, and knowledge about sexuality, hence STDs. Although the Middle East and North Africa (MENA) region is regarded as the least affected area from HIV and STDs, there are many serious, obvious or hidden risk factors and the epidemic is growing in the MENA region (6). Cyprus is located at the borders of this area and Turkish Cypriots have many similarities with MENA region people such as religion and traditions. According to the results of our literature search, there has not been any report about the epidemiology or sexual behaviour of Turkish Cypriots published so far.

The aim of this study is to determine knowledge, attitudes and behaviour of Turkish Cypriot adolescents related to STDs and HIV, as an initial effort before developing educational and awareness raising activities. So, it will be a good opportunity to prevent STDs by focusing on the sexual education of young adolescents who are candidates of future STDs.

\section{MATERIALS AND METHODS}

This cross sectional, descriptive study was carried out among the high school students in the largest high school at the centre of Nicosia, in North Cyprus. Data were collected on the voluntary basis by questionnaires. The questionnaires were prepared after a pubmed search and modifications were made to the ones that were used in the previous studies. A semi structured and self-administered questionnaire was used for data collection. Questionnaires were filled in anonymously, including demographic features in the first part. The second part of the questionnaire consisted of 15 multiple-choices questions prepared to determine the level of knowledge on STDs, attitudes and behaviour. The questionnaire was elicited if the student needed to get information about STDs or had knowledge on STDs (e.g. ability to identify STDs, to describe means of transmission, and preventive measures); and what his/ her sources of information on STDs were. Only "yes" answers were accepted as "knowing" for yes/no questions. In multiple choices, only correct answer was accepted as "knowing". A total of 450 questionnaires were applied to the students and 423 (94\%) of them were answered completely. Primarily descriptive statistics were used for data analysis. Chi-square test and SPSS 12 version software programme were used for statistical analysis.

\section{RESULTS}

In this study, 423 of 450 (94\%) students answered the questionnaire. They were between $14-17$ years of age with a mean of $15.61 \pm 1.22$ years. There were 212 female $(50.12 \%)$ and 211 male $(49.88 \%)$ students involved in the study.

\section{Knowledge Level}

The majority of students $(91.25 \%)$ stated that they had knowledge about STDs, and $8.75 \%$ of them did not have any knowledge at all. Most of the adolescents (54.4\%) consider their STDs knowledge moderate whilst $32.7 \%$ of male students think that they have full knowledge on STDs. The respective proportion of girls was only 6.6 . Among the female students, $13.68 \%$ had no information about STDs at all (Table 1).

Regarding knowledge on other means of transmission through which STDs could be a risk factor, $62.3 \%$ of students responded positively. However, the relationship between STDs and drug usage was not known to $1.65 \%$ of the students.

Unprotected sexual intercourse was recognized as the most frequent mode of infection transmission (92.67\%), followed by blood transmission (72.10\%), oral sex (39.72\%), kissing (28.13\%), and protected sexual intercourse $(8.51 \%)$, respectively.

The most known STD was AIDS (91.96\%). Molluscum contagiosum was reported to be known as an STD by $52.72 \%$ of students, followed by gonorrhea (48.23\%), bacterial vaginosis (44.21\%), hepatitis B $(28.61 \%)$, genital warts/HPV infection (24.35\%), syphilis $(21.04 \%)$, and trichomoniasis (20.33\%). The other diseases known as STDs were reported as follows: Hepatitis C (18.68\%), Hepatitis A (18.44\%), Herpes infections (13.7\%), and Chlamydial diseases $(6.86 \%)$. Students marked also some other diseases that may in their opinion be sexually transmitted (brucellosis $7.09 \%$, tuberculosis $7.8 \%$, and Rotavirus infections 6.86\%).

The most expected benefit to the prevention of STDs was reported as "reducing the spread of AIDS" by $81.09 \%$ of the students; other benefits included "maintaining a healthy sexual life" (65.96\%), "protecting public health" $(49.65 \%)$, "delivering a healthy child" (32.86\%), "reducing development of genital cancers" $(30.26 \%)$, and "reducing other problems related to reproductive systems" (28.19\%). The answers to the question "what is in your opinion required following suspicion of a risky sexual contact" are shown in Table 2. The most common answer was to consult a doctor. However, there were differences in the other behavioural patterns of male and female groups as shown in Table 2.

Table 1. Demographic data of the students and their responses regarding information on STDs

\begin{tabular}{|l|c|c|c|c|c|c|}
\hline $\begin{array}{l}\text { Sex and age of } \\
\text { students }\end{array}$ & $\begin{array}{c}\text { Number of } \\
\text { students (\%) }\end{array}$ & Mean age & $\begin{array}{c}\text { No information } \\
(\%)\end{array}$ & $\begin{array}{c}\text { Little information } \\
(\%)\end{array}$ & $\begin{array}{c}\text { Medium level } \\
\text { information (\%) }\end{array}$ & $\begin{array}{c}\text { Full information } \\
(\%)\end{array}$ \\
\hline Female & $212(50.12)$ & $15.47 \pm 1.23$ & 13.68 & 23.11 & 56.60 & 6.6 \\
\hline Male & $211(49.88)$ & $15.75 \pm 1.19$ & 8.75 & 17.73 & 54.14 & 19.62 \\
\hline 14 years & $104(24.58)$ & & 11.53 & 15.38 & 61.53 & 11.53 \\
\hline 15 years & $105(24.82)$ & & 13.33 & 21.50 & 47.61 & 17.14 \\
\hline 16 years & $72(17.02)$ & & 9.72 & 26.38 & 48.61 & 15.27 \\
\hline 17 years & $142(33.56)$ & & 2.42 & 11.97 & 56.34 & 29.58 \\
\hline
\end{tabular}


Table 2. Students' responses to the question "what is your reaction if there is a suspicion of a risky sexual contact"

\begin{tabular}{|l|c|c|c|}
\hline Answer & Total (\%) & Male (\%) & Female (\%) \\
\hline Share the problem with his/her family & 30.26 & 25.11 & 35.38 \\
\hline Consult a doctor & 71.39 & 72.03 & 70.75 \\
\hline Ask friends and follow their advices & 12.53 & 19.90 & 5.19 \\
\hline Make an internet search and apply self treatment & 15.60 & 20.37 & 10.85 \\
\hline Wait for the symptoms of disease & 8.04 & 7.10 & 8.96 \\
\hline Do not do anything and carry on with his/her life & 2.13 & 3.31 & 0.94 \\
\hline
\end{tabular}

\section{Source of Knowledge}

School was the most frequently mentioned source for knowledge gain. However, $43.12 \%$ of male students reported internet as a secondary main source of knowledge. Medical authorities were reported as the least source of knowledge for both male and female students (7.57\%). Interestingly, many of the students from both genders could not talk to their parents about STDs (77.07\%).

\section{Treatment History}

None of the female students have undergone a treatment for STDs until now, but $4.73 \%$ of male students reported previous treatments for STDs. The age of the latter group of previously treated male students was 17.

\section{Attitude: Necessity of Education}

Most of the students agreed on the need of education about STDs (93.14\%). Both male and female groups preferred the education during the high school ages (67.14\%). Only $21.28 \%$ would prefer an earlier education, and the remainder $4.26 \%$ preferred an education at university time.

Most of the students were eager to join educational activities, if there are any, about STDs (69.74\%). 25 females (11.79\%) and and 8 males $(3.79 \%)$ agreed to join activities only with the same gender. 18 students $(4.26 \%)$ were not willing to join these educations because of shyness.

\section{DISCUSSION}

STDs target mostly teenagers and young adults, at the age of the highest productive and reproductive activity. WHO defines adolescence as the period of life between 10 and 19 years of age. In the early adolescence, which is in the beginning of second decade, secondary sex characteristics develop jointly with rapid physical growth. Middle adolescence begins approximately at the age of 14 years, ends around the age of 17 to 18 years. Also, increased sexual interest and non-coital sexual behaviours are characteristic for this period (1). Early and middle adolescents are less likely than others to use preventive methods when engaging in sexual intimacy and more likely to deny symptoms of infection (7). Although the average age of first coitus is not certainly known among Turkish Cypriot adolescents, it may be suspected to be lower than in other Islamic countries because of the multicultural life style and mild effect of religion on daily life in the island. Even though we do not have any data regarding the sexual behaviour and risk patterns of Turkish Cypriot adolescents, because of the similar ethnic and geographic properties and close relationship with Turkey, there may be similarities. In a very recent study, Turkish university students were shown to be under serious risk of sexually transmitted diseases (8). Moreover, North Cyprus is one of the destinations of women from Eastern Europe seeking economic opportunities abroad as sex workers (5).

This study objective was to show the high school students sources of information and knowledge of the STDs issue. The knowledge of STDs is considered to be inadequate for a multicultural country especially with regards to girls. Our study revealed that girls are not as knowledgeable as boys. Pre-marital sex among women is strongly condemned in the Turkish Cypriot society, while in young men it is either condoned or openly encouraged. This results in a significant demand for sexual services on the part of young men (5). Female adolescents being oblivious to sexually transmitted diseases may be related to these unspoken limits. These results are similar and comparable with some studies from Turkey $(9,10)$. However, studies from Europe point out the opposite of this data $(11,12)$. Diversity between the countries may stem from religious differences between them, as the high school students in this study were Muslims. A study from the United Arab Emirates, that is also an Islamic country, showed similar results as our study did (13).

The study revealed that the majority of students had heard about STDs, though none of them mentioned parents or relatives as a source of information like in the other findings (14). They represent a new generation of productive adults who can help in their communities' progress. The other cause of the inferiority of STDs knowledge is the barrier between parents and children to discuss matters related to sexual relationship. In contrast, school is the most important STDs related knowledge source for the majority of respondents. Specialists such as health care workers had less importance. These results coincide with other studies from Turkey $(9,10,15)$. Also, Samkange-Zeeb et al. after reviewing 15 studies from all around Europe, implicated importance of school settings to play an important role in the education about STDs, which is similar to our results (12). We may say that, in the adolescence period that is based on development and interaction, the importance of school is obvious as a means of promoting information about STDs. Also, there was noted that very little communication regarding STDs occurred between specialist institutions and persons or their family. It has become obvious that health care workers should be more involved in STDs education and development of high school educational programmes. However, as some students defined other diseases as STDs, indicating that usage of names of STDs may not really help in designing educational material. 
Using the local terms of diseases with good definitions may be effective to avoid misunderstandings. The educational material should be designed including health information and visual material may be added to define the situations effectively. Hovewer, Kopacz revealed that teenage magazines hold the potential for influencing adolescent sexual behaviour and development (16). The information should be delivered in a fast, memorable and ethically acceptable manner. As the results of our study showed that Turkish Cypriot adolescents would be eager to learn more about STDs and do not have strict attitudes about sexuality. This may be an opportunity to control further spread of STDs among new generations.

While none of the female students had been treated for STDs, $4.73 \%$ of male students had undergone treatment for STDs. This rate is very low for male students. Nevertheless, most of the female students couldn't describe the symptoms and this could be the cause of lower degree of treatment (17).

In our study, the respondents desired to learn more about STDs. This indicates that reports dealing with the rapid spread of STDs like AIDS in various populations as well as in the Turkish and Turkish Cypriot population have increased the level of anxiety over contagion among the respondents. STDs risk factors knowledge question could not be answered correctly enough by the students. These findings showed the need of educational activities aimed at STDs issues.

The most recognised mode of infection reported was unprotected sexual intercourse and this is in parallel with the most recognised STD i.e. HIV. Hovewer, almost half of the students do not know the rest of the STDs and this could create a meaningless sense of confidence as the other STDs like molluscum contagiosum, HPV and Herpes simplex virus infections could be transmitted via direct contact. In 2001, Samkange-Zeeb et al. reviewed the reports regarding the knowledge and awareness of adolescents towards STDs in all around Europe and compared 15 of them (12). In this review, HIV was the most known STD which was also widely reported in our study. This may be related to the global actions and campaigns against AIDS and shows that these actions reach its target. This finding concerning other STDs except AIDS also correlates with other European studies, reporting awareness level as low as 5.4\% (18). The level of other STDs related knowledge was relatively low in our study. In the questionnaire form of our study, the adolescent had to choose STDs from a given list of diseases. Such closed questions are more practical, time saving and easier, both in terms of answering and analysing. But open questions are suggested to be more reliable for surveying participants with unknown level of knowledge. So, the real level of knowledge about the STDs might be estimated to be lower than reported.

Nevertheless, our findings indicated that Turkish Cypriot high school students are well knowledgeable about HIV and AIDS. But in a report from Croatia in 2010, the most common STDs among adolescents were chlamydia, gonorrhea, human papillomavirus infection, and trichomoniasis (19). Participants in our study had a knowledge gap about other STDs existence and their individual risk perception was very low. Because of these findings, training for students about the other STDs should be encouraged and increased. The findings also correlates with a Turkish study in which high school students' low baseline knowledge was shown despite good ability to learn. A school-based reproductive health education is needed to promote knowledge and prevention in reproductive health among teenagers. The study revealed that the respondents are willing to learn more about STDs.

Our study also has some limitations. First, sampling is done from one school in a big city, which could overlook the attitudes in rural areas. Second, data collection was done by a voluntarily filled-in questionnaire which reflects the subjective attitudes of the responding students. Therefore, during interpretation and application of the results of this study, this should be taken into account. Despite these limitations, this study provides important information about the attitudes of Turkish Cypriot adolescents towards STDs in Cyprus.

\section{CONCLUSION}

This is the first and unique study from the North Cyprus, which points to some major priorities, such as the need of education about STDs transmission and prevention among young people. Well designed educational programmes should be organised before initiation of sexual relationship in order to prevent risky behaviour among adolescents and to reduce the number of risky behaviour among youth who are already sexually active. As a result, STDs education should be perceived as an powerful way of fighting STDs in the region.

\section{Conflict of Interest}

None declared

\section{REFERENCES}

1. Sexually Transmitted Diseases Services [Internet]. Adelaide: STD Services, Royal Adelaide Hospital [cited 2013 Jan 4]. Adolescent sexual behavior information for students. Available from: http://www.stdservices. on.net/std/social_aspects/adolescents.htm.

2. Eng TR, Butler $\bar{W}$ T, editors. The hidden epidemic: confronting sexually transmitted diseases. Washington: National Academy Press; 1997.

3. Cates W Jr., et al. Epidemiology of sexually transmitted diseases and STD sequelae. In: Hitchcock PJ, et al, editors. STDs and adolescents: challenges for the 21st Century. New York: Oxford University Press; 1998.

4. United Nations Peacekeeping Force in Cyprus [Internet]. Nicosia: UNFICYP [cited 2013 Jan 4]. History. Available from: http://www.unficyp. org.

5. Güven-Lisaniler F, Rodríguez L, Uğural S. Migrant sex workers and state regulations in North Cyprus. Womens Stud Int Forum. 2005;28(1):79-91.

6. McFarland W, Abu-Raddad LJ, Mahfoud Z, DeJong J, Riedner G, Forsyth A, et al. HIV/AIDS in the Middle East and North Africa: new study methods, results, and implications for prevention and care. AIDS. 2010 Jul;24 Suppl 2:S1-4.

7. Biro FM, Dorn LD. Puberty and adolescent sexuality. Pediatr Ann. 2005 Oct;34(10):777-84.

8. Golbasi Z, Kelleci M. Sexual experience and risky sexual behaviours of Turkish university students. Arch Gynecol Obstet. 2011 Mar;283(3):5317.

9. Golbasi Z, Taskin L. Evaluation of school-based reproductive health education program for adolescent girls. Int J Adolesc Med Health. 2009 Jul-Sep;21(3):395-404.

10. Gökengin D, Yamazhan T, Ozkaya D, Aytuğ S, Ertem E, Arda B, et al. Sexual knowledge, attitudes, and risk behaviors of students in Turkey. J Sch Health. 2003 Sep;73(7):258-63.

11. Merakou K, Costopoulos C, Marcopoulou J, Kourea-Kremastinou J. Knowledge, attitudes and behaviour after 15 years of HIV/AIDS prevention in schools. Eur J Public Health. 2002 Jun:12(2);90-3.

12. Samkange-Zeeb FN, Spallek L, Zeeb H. Awareness and knowledge of sexually transmitted disease (STDs) among school-going adolescents in 
Europe: a systematic review of published literature. BMC Public Health. 2011 Sep 25;11:727.

13. Gańczak M, Barss P, Alfaresi F, Almazrouei S, Muraddad A, Al-Maskari F. Break the silence: HIV/AIDS knowledge, attitudes, and educational needs among Arab university students in United Arab Emirates. J Adolesc Health. 2007 Jun;40(6):572.e1-8.

14. Aboyeji AP, Adegoke AA, Adebisi SA. Sexual behaviour and knowledge of sexually transmitted diseases among female adolescents in Ilorin Kwara State. Trop J Med Res. 2004:8(1);10-6.

15. Ayranci U. AIDS knowledge and attitudes in a Turkish population: an epidemiological study. BMC Public Health. 2005 Sep 13;5:95.

16. Kopacz MS. Sexual development and behaviour issues in Polish teenage magazines. Cent Eur J Public Health. 2006 Dec;14(4):193-9.
17. Mwambete KD, Mtaturu Z. Knowledge of sexually transmitted diseases among secondary school students in Dar es Salaam, Tanzania. Afr Health Sci. 2006 Sep;6(3):165-9.

18. Höglund AT, Tydén T, Hannerfors AK, Larsson M. Knowledge of human papillomavirus and attitudes to vaccination among Swedish high school students. Int J STD AIDS. 2009 Feb;20(2):102-7.

19. Ljubojević S, Lipozenčić J. Sexually transmitted infections and adolescence. Acta Dermatovenerol Croat. 2010;18(4):305-10.

Received June 27, 2012 Accepted in revised form January 4, 2013 